\title{
Global factor trade with differentiated factor prices and factor intensities*
}

\author{
Yun-kwong Kwok ${ }^{\dagger}$ \\ Deakin University, Australia
}

December 1, 2003

\begin{abstract}
The assumption of internationally identical factor intensity techniques may be one of the major causes of the HOV model's poor performance. To relax this assumption, detailed input-output data are required to compute the factor intensity techniques used in different countries; however, these data are not readily accessible for many countries. This paper takes an alternative approach by introducing an inferring method that can infer the factor intensity techniques of different countries based on our knowledge about the US factor intensity techniques and the international factor price differences. The original HOV model is then modified accordingly.
\end{abstract}

J.E.L. Classification: F1; F11; D2; D5

Keywords: Heckscher-Ohlin-Vanek (HOV) model; factor content of trade; international factor intensity technique differences; international factor price differences

${ }^{*}$ This paper is adapted from my dissertation written at the University of Virginia. I am indebted to my advisors, John McLaren, Jinill Kim, and Paolo Ramezzana, for valuable suggestions. I would also like to thank Simon Anderson, Eden Yu, Kenneth Chan, E. Kwan Choi, Murray Kemp, Hamid Beladi, Martin Richardson, Amy Glass, Jeffrey Reimer, participants of the Fall 2003 Midwest International Economics Group Meeting, the Second International Conference on Recent Advances in International Economics at the City University of Hong Kong, and seminars at the University of Virginia for helpful comments. All remaining errors are the author's. Funding from the Bankard Fund for Political Economy is gratefully acknowledged.

${ }^{\dagger}$ Correspondence: School of Accounting, Economics and Finance, Deakin University, 221 Burwood Highway, Burwood, Victoria, Australia 3125. Tel: 61-3-924-46540. Fax: 61-3-924-47243. Email: yunkwokw@deakin.edu.au 


\section{Introduction}

The Heckscher-Ohlin-Vanek (HOV) model predicts that a country will export services of factors that are relatively abundant in the country and will import services of factors that are relatively scarce in the country. Although this model has been the mainstay of international economic theories for many decades, many empirical studies found that its predicted factor services embodied in trade is far from matching the measured factor services embodied in trade (e.g. Leontief (1953), Maskus (1985), Bowen, Leamer, and Sveikauskas (1987), Staiger (1988), Trefler (1995), and Estevadeordal and Taylor (2002)).

The poor performance of the HOV model can be summarized in the following studies. Bowen et al. (1987) found that the ranking of net exports of factor services did not conform to the ranking of the relative abundance of factor endowments. That means larger endowed factors did not seem to play a more important role in a country's net exports. Bowen et al. even found that, in around half of the cases, the sign of the net exports did not match the sign of the relative factor endowments. That is, in many cases, countries were actually exporting services of their scarce factors rather than services of their abundant factors. Trefler (1995) later discovered that the measured factor content of trade was extraordinarily small relative to the HOV predicted factor content of trade, a discrepancy that Trefler called "the mystery of missing trade."

In most of the empirical studies that showed the failure of the HOV model, the factor content of trade was measured in a way that all countries were assumed to apply the same US factor intensity techniques. They made this assumption because the HOV model assumes factor price equalization (FPE) holds. Most of these studies concluded that the identical factor intensity techniques assumption may be one of the main reasons for the failure of the HOV model. By studying the trade of Japanese regions, Davis, Weinstein, Bradford, and Shimpo (1997) found that the HOV model performed quite well when FPE was assumed to hold only among regions in Japan; however, when FPE was assumed to hold across countries, the model gave the same poor results. This reinforced the idea that the failure of the HOV model probably stem from the assumption of FPE.

To relax the assumption of identical factor intensity techniques, we need to compute the actual factor intensity techniques applied by each individual country. This requires detailed input-output tables and factor usage data by country; however, these data are unavailable for many countries, especially the developing countries. Even for countries that publish these data, many data are either expensive or not in satisfactory forms that are readily for use in HOV analysis. Davis and Weinstein (2001) and Hakura (2001) collected input-output data of various countries and found that the performance of the HOV model is significantly improved when the model allows for differentiated factor intensity techniques. Their findings are important; however, the country sample that provided input-output data in their studies is not large, and 
most of the countries are rich OECD countries.

This paper takes an alternative approach by introducing an inferring method that can allow us to derive the different factor intensity techniques applied in all countries over the world. The method infers the factor intensity techniques of other countries based on our knowledge of the US factor intensity techniques and the relative factor prices across countries. The rationale is that, whichever country they are in, industries will employ factors to a level such that the marginal rate of substitution in production equals the relative factor price in that country. Therefore, by observing the US factor intensity techniques chosen by US industries in response to the US relative factor prices, we should be able to infer the factor intensity techniques chosen by other countries' industries in response to other countries' relative factor prices.

Using the factor intensity technique inferring method, this paper inferred the factor intensity techniques of 69 countries. The original HOV model was then modified to adapt these inferred factor intensity techniques. The modified model significantly improved the prediction of the original HOV model in terms of both trade directions and trade volumes.

Although the goal of bringing in this factor intensity technique inferring method is to modify the original HOV model and enhance its power in predicting global factor trade, it may also be interested to apply this method in many other fields. If factor prices, or proxies of them, are available, this method can be applied in fields such as international productivity comparisons in development economics, factor employment analyses in labor economics and empirical IO, and historical productivity change investigations in economic history.

The paper is organized as follows. The next section introduces the original HOV model. It also demonstrates the variation in relative factor prices across countries and shows how the identical factor intensity techniques assumption affects the empirical performance of the HOV model. The third section brings in the factor intensity technique inferring method and a modified HOV model that adapts the inferring method. The fourth section compares the empirical performance between the original HOV model and the modified HOV model. The final section contains the concluding remarks.

\section{Implications of factor intensity techniques}

\subsection{The original HOV model}

In a $C$-country $I$-commodity $F$-factor model, the net exports of country $c$ is

$$
\mathbf{E X}_{c}-\sum_{c^{\prime}, c^{\prime} \neq c} \mathbf{I M}_{c c^{\prime}}=\mathbf{Q}_{c}-\mathbf{D}_{c}
$$

where $\mathbf{E X}_{c}$ and $\mathbf{I M}_{c c^{\prime}}$ are $(I \times 1)$ vectors of exports and imports. Subscript $c c^{\prime}$ is used to indicate that the commodities imported by country $c$ are coming from country $c^{\prime}$. 
$\mathbf{Q}_{c}$ and $\mathbf{D}_{c}$ are vectors of country c's commodity output and commodity absorption.

The relative prices of tradable goods across countries are equalized by free trade. The original HOV model assumes all countries have the same technology and the factor endowments of all countries lie within the cone of diversification. As a result, free trade causes the FPE to hold and the relative prices of nontradable goods across countries are equalized by perfect competition. With the same relative commodity prices, plus the standard assumption of identical homothetic taste across the world, $\mathbf{D}_{c}=s_{c} \mathbf{Q}_{w}$, where $s_{c}$ is country c's share of world absorption and $\mathbf{Q}_{w}=\sum_{c} \mathbf{Q}_{c}$ is the vector of world output.

Let $\mathbf{A}_{c}$ be the $(F \times I)$ factor intensity matrix of country $c$ that tells us the costminimizing factor input requirements of producing each unit of final output in country c. Production functions are assumed to be constant returns to scale, so that $\mathbf{A}_{c}$ is independent of the production scale. As the FPE holds across countries, the same factor intensity techniques, $\mathbf{A}$, is shared by all countries. In most of the previous studies, the US factor intensity matrix, $\mathbf{A}_{u s}$, was chosen to be the international common matrix, A. Under the assumption of full employment, the relationship between the factor services embodied in trade and the relative factor endowments can be obtained by premultiplying the both sides of equation (1) by $\mathbf{A}_{u s}$. The original HOV model thus states that

$$
\mathbf{A}_{u s} \mathbf{E X}_{c}-\sum_{c^{\prime}, c^{\prime} \neq c} \mathbf{A}_{u s} \mathbf{I M}_{c c^{\prime}}=\mathbf{V}_{c}-s_{c} \mathbf{V}_{w}
$$

where $\mathbf{V}_{c}$ is the $(F \times 1)$ vector of factor endowments of country $c$ and $\mathbf{V}_{w}=\sum_{c} \mathbf{V}_{c}$ is the total factor endowments in the world. For a particular factor $f$ :

$$
\sum_{i} a_{f i, u s} E X_{i, c}-\sum_{c^{\prime}, c^{\prime} \neq c} \sum_{i} a_{f i, u s} I M_{i, c c^{\prime}}=V_{f, c}-s_{c} V_{f, w}
$$

where $a_{f i, u s}$, an element in $\mathbf{A}_{u s}$, is the amount of factor $f$ used by industry $i$ in the US to produce one unit of output. The HOV model predicts that, if country $c$ is relatively abundant in factor $f\left(V_{f, c}>s_{c} V_{f, w}\right)$, services of factor $f$ embodied in its exports will be larger than that embodied in its imports $\left(\sum_{i} a_{f i, u s} E X_{i, c}>\sum_{c^{\prime}, c^{\prime} \neq c} \sum_{i} a_{f i, u s} I M_{i, c c^{\prime}}\right)$; if country $c$ is relatively scarce in factor $f\left(V_{f, c}<s_{c} V_{f, w}\right)$, the reverse will be true.

To test the HOV model empirically, data of factor intensity techniques, trade, and factor endowments were collected separately from independent sources and plugged into the left-hand side and the right-hand side of equation (3). Conventionally, the left-hand side is denoted as the measured factor content of trade $(M F C T)$ and the right-hand side is denoted as the predicted factor content of trade (PFCT). As many empirical studies have shown, the performance of the HOV model is disappointing. Bowen et al. (1987) found that, in many cases, the sign of the MFCT did not conform to the sign of the $P F C T$. Trefler (1995) found that the absolute value of the $M F C T$ is extraordinarily small relative to the absolute value of the $P F C T$. 


\subsection{Global factor price inequalities}

The assumption of identical factor intensity techniques across countries may be one of the reasons for the poor performance of the HOV model. Countries will apply the same factor intensity techniques only when the FPE holds. However, when we look around the world, we see huge deviations in factor prices across countries.

Table 1a lists the ratios of factor prices in different countries to that in the US. Table $1 \mathrm{~b}$ lists the ratios of relative factor prices in different countries to that in the US, where the relative factor price is the factor price of each category of labor relative to the factor price of capital. If the FPE holds, all values in Table 1a and 1b should be equal to 1; however, by comparing the mean, the median, and the quartiles with 1 , we can see the variations in factor prices were huge. Table 1a shows that, for all factors, the US factor prices were higher than the mean of the factor prices of all countries. The relative factor prices, which determine the choice of factor intensity techniques, also varied significantly across countries. Table $1 \mathrm{~b}$ shows that, relative to the investment price of capital, the US relative wages of various categories of labor were higher than the mean relative wages of all countries by approximately one standard deviation. All ratios differed drastically from 1, the case for FPE.

The factor prices are not exogenous and their inequalities across countries can be caused by many factors. Huge dissimilarity in relative factor endowments across countries, which brings about either specializations or factor intensity reversals, is an explanation that is consistent with the HOV theory. Various kinds of trade impediments can also be explanations for that. ${ }^{1}$ A detailed investigation of the sources of factor price inequality is out of the scope of this paper. The important thing is, under the assumption of perfect competition, industries in different countries take the relative factor prices they are facing as given. The differences in relative factor prices drive industries in different countries to adopt different factor intensity techniques. Therefore, the $M F C T$ on the right hand side of equation (2) should be $\mathbf{A}_{c} \mathbf{E X}_{c}-\sum_{c^{\prime}, c^{\prime} \neq c} \mathbf{A}_{c^{\prime}} \mathbf{I M}_{c c^{\prime}}$. Assuming all countries sharing the same factor intensity techniques $\left(=\mathbf{A}_{u s}\right)$ will give a biased measurement of the factor content of trade.

\subsection{HOV without FPE}

Unlike the original HOV model, when there is no FPE, prices of nontradable goods will be different across countries and the factor content of each country's nontradable goods absorption will no longer be equal to the factor content of the country's share of world nontradable goods absorption; therefore, we need to set apart nontradable goods from tradable goods.

This paper assumes the same type of tradable goods produced in different countries are differentiated to a certain extent, even if the goods are assorted into the

\footnotetext{
${ }^{1}$ In this case, we assume the impact of trade impediments on commodity prices are not big enough to alter the shares of commodity absorption in different countries, but are big enough to alter the factor intensities adopted by industries in different countries.
} 
same commodity division at the most disaggregated industrial classification level. With this assumption in addition to the standard assumptions of identical homothetic taste and zero trade cost, country $c$ consumes the same share, $s_{c}^{T}$, of each type of tradable goods produced in each country. The factor content of trade can be expressed as

$$
\begin{aligned}
\mathbf{A}_{c} \mathbf{E X}_{c}-\sum_{c^{\prime}, c^{\prime} \neq c} \mathbf{A}_{c^{\prime}} \mathbf{I M}_{c c^{\prime}} & =\left[\begin{array}{ll}
\mathbf{A}_{c}^{T} & \mathbf{A}_{c}^{N}
\end{array}\right]\left[\begin{array}{c}
\mathbf{Q}_{c}^{T}-s_{c}^{T} \mathbf{Q}_{c}^{T} \\
\mathbf{Q}_{c}^{N}-\mathbf{Q}_{c}^{N}
\end{array}\right]-\sum_{c^{\prime}, c^{\prime} \neq c}\left[\begin{array}{ll}
\mathbf{A}_{c^{\prime}}^{T} & \mathbf{A}_{c^{\prime}}^{N}
\end{array}\right]\left[\begin{array}{c}
s_{c}^{T} \mathbf{Q}_{c^{\prime}}^{T} \\
\mathbf{0}
\end{array}\right] \\
& =\mathbf{V}_{c}^{T}-s_{c}^{T} \mathbf{V}_{w}^{T},
\end{aligned}
$$

where the superscripts $T$ and $N$ are used to indicate tradable goods and nontradable goods respectively. $\quad \mathbf{V}^{T}$ is the amount of factors employed in the tradable goods industries. Since the FPE does not hold, the relative price of nontradable goods to tradable goods will normally vary across countries. This paper follows Davis and Weinstein (2001) and assumes the preferences in all countries between tradable goods and nontradable goods are identical and Cobb-Douglas. Under this assumption, country $c$ 's share of world absorption, $s_{c}$, is also country $c$ 's share of world spending on tradable goods. Then, the relationship between the factor content of trade and the relative factor endowments can be rewritten as

$$
\mathbf{A}_{c} \mathbf{E X}_{c}-\sum_{c^{\prime}, c^{\prime} \neq c} \mathbf{A}_{c^{\prime}} \mathbf{I} \mathbf{M}_{c c^{\prime}}=\mathbf{V}_{c}-s_{c} \mathbf{V}_{w}-\left(\mathbf{V}_{c}^{N}-s_{c} \mathbf{V}_{w}^{N}\right)
$$

where $\mathbf{V}^{N}$ is the amount of factors employed in the nontradable goods sectors.

When the FPE holds, the relative prices of nontradable goods are equalized across countries such that $\mathbf{D}_{c}^{N}=s_{c} \mathbf{Q}_{w}^{N}$. By definition, output always equals demand for nontradable goods in each country and $\mathbf{Q}_{c}^{N}=s_{c} \mathbf{Q}_{w}^{N}$. With identical factor intensity techniques, $\mathbf{V}_{c}^{N}=s_{c} \mathbf{V}_{w}^{N}$. Therefore, when the FPE holds, equation (4) returns to equation (2) and the original HOV model is valid.

\section{The modified HOV model}

To correctly measure the factor content of trade, we need to compute $\mathbf{A}_{c}$ separately for different countries. This requires detailed input-output tables and factor usage data for each country $c$. Nonetheless, these data are not easily obtained. This paper takes an alternative approach by introducing a factor intensity technique inferring method. Based on the US factor intensity matrix, $\mathbf{A}_{u s}$, and the relative factor prices across countries, the inferring method can allow us to infer the factor intensity matrices, $\mathbf{A}_{c}$, of all countries in the world.

The HOV model is then modified to affix the factor intensity technique inferring method. In contrast with the original HOV model, which relates three important objects: trade, endowments, and technology of a single country, the modified HOV 
model here adds one more item to it: the international relative factor prices. Hereafter, the modified HOV model will be called the $\mathrm{HOV}(\mathrm{w})$ model, where the "w" is used to indicate that factor prices are used in deriving the differentiated factor intensity techniques in the modified model. The HOV $(w)$ model relates four important objects: trade, endowments, technology of a single country, and factor prices.

\subsection{Inferring factor intensity techniques}

As defined in section 2.1, the amount of factor $f$ required to produce one unit of commodity $i$ is $a_{f i, c}$. Let the production function of industry $i$ takes the CES form:

$$
1=Q_{i}\left(a_{1 i, c}, a_{2 i, c}, \ldots, a_{F i, c}\right)=A_{i}\left[\sum_{l=1}^{F} \phi_{l i} a_{l i, c}^{\rho_{i}}\right]^{1 / \rho_{i}}, \quad \rho_{i} \in(-\infty, 1] .
$$

The marginal value product of factor $k$ in industry $i$ is $p_{i, c}\left[\sum_{l=1}^{F} \phi_{l i} a_{l i, c}^{\rho_{i}}\right]^{-1} \phi_{k i} a_{k i, c}^{\rho_{i}-1}$, where $p_{i, c}$ is the price of commodity $i$ in country $c$. By cost minimization, industry $i$ chooses a combination of inputs of factor $k$ and factor $l$ such that

$$
\frac{w_{k, c}}{w_{l, c}}=\frac{\phi_{k i}}{\phi_{l i}}\left(\frac{a_{l i, c}}{a_{k i, c}}\right)^{1-\rho_{i}}
$$

where $w_{f, c}$ is the nominal factor price of $f$ in country $c .^{2}$

All countries are assumed to have the same technology in the sense that the values of the parameters, $A_{i}, \phi_{f i}$, and $\rho_{i}$, are the same across countries. However, this does not imply that countries must be producing commodities with the same factor intensity techniques. That is, different factor intensity ratios, $\left(a_{l i, c} / a_{k i, c}\right)$, can be chosen even when industry $i$ in all countries are operating under the same production function. Due to the large inequality in relative factor prices, industry $i$ in each country chooses its own factor intensity technique such that the marginal rate of substitution in production equals the relative factor prices in its own country (equation (6)).

Since equation (6) is true for all countries and all countries are sharing the same production function, we have the relationship between the factor intensity ratios applied in country $c$ and that in the US:

$$
\frac{a_{k i, c}}{a_{l i, c}}=\left(\frac{w_{l, c}}{w_{l, u s}}\right)^{1 /\left(1-\rho_{i}\right)}\left(\frac{w_{k, u s}}{w_{k, c}}\right)^{1 /\left(1-\rho_{i}\right)}\left(\frac{a_{k i, u s}}{a_{l i, u s}}\right) .
$$

Based on equation (5), when both country $c$ and the US are on the same unit isoquant,

$$
\sum_{l=1}^{F} \phi_{l i} a_{l i, c}^{\rho_{i}}=\sum_{l=1}^{F} \phi_{l i} a_{l i, u s}^{\rho_{i}}
$$

\footnotetext{
${ }^{2}$ Assume the factor prices within each country are the same across industries.
} 
Extract $a_{k i}$ from both sides of equation (8) such that

$$
a_{k i, c}^{\rho_{i}} \sum_{l=1}^{F} \phi_{l i}\left(\frac{a_{l i, c}}{a_{k i, c}}\right)^{\rho_{i}}=a_{k i, u s}^{\rho_{i}} \sum_{l=1}^{F} \phi_{l i}\left(\frac{a_{l i, u s}}{a_{k i, u s}}\right)^{\rho_{i}} .
$$

Using (7), we get

$a_{k i, c}^{\rho_{i}} \sum_{l=1}^{F}\left[\phi_{l i}\left(\frac{w_{l, c}}{w_{l, u s}}\right)^{-\rho_{i} /\left(1-\rho_{i}\right)}\left(\frac{w_{k, u s}}{w_{k, c}}\right)^{-\rho_{i} /\left(1-\rho_{i}\right)}\left(\frac{a_{k i, u s}}{a_{l i, u s}}\right)^{-\rho_{i}}\right]=a_{k i, u s}^{\rho_{i}} \sum_{l=1}^{F} \phi_{l i}\left(\frac{a_{l i, u s}}{a_{k i, u s}}\right)^{\rho_{i}}$.

By rearranging terms,

$$
\left(\frac{a_{k i, c}}{a_{k i, u s}}\right)^{\rho_{i}}\left(\frac{w_{k, u s}}{w_{k, c}}\right)^{-\rho_{i} /\left(1-\rho_{i}\right)} \sum_{l=1}^{F}\left[\left(\frac{w_{l, c}}{w_{l, u s}}\right)^{-\rho_{i} /\left(1-\rho_{i}\right)} \phi_{l i} a_{l i, u s}^{\rho_{i}}\right]=\sum_{l=1}^{F} \phi_{l i} a_{l i, u s}^{\rho_{i}} .
$$

Substitute $w_{l, c}$ and $w_{l, u s}$ by corresponding marginal value products of factor $l$ and rearrange the terms using (8) and the assumption of same production function, equation (9) becomes

$$
\left(\frac{a_{k i, c}}{a_{k i, u s}}\right)^{\rho_{i}}\left(\frac{w_{k, u s}}{w_{k, c}}\right)^{-\rho_{i} /\left(1-\rho_{i}\right)}\left(\frac{p_{i, c}}{p_{i, u s}}\right)^{-\rho_{i} /\left(1-\rho_{i}\right)} \sum_{l=1}^{F} \phi_{l i} a_{l i, u s}^{\rho_{i}}=\sum_{l=1}^{F} \phi_{l i} a_{l i, u s}^{\rho_{i}}
$$

and the factor intensity coefficient, $a_{k i, c}$, of industry $i$ in country $c$ is solved:

$$
a_{k i, c}=a_{k i, u s}\left(\frac{w_{k, u s} / p_{i, u s}}{w_{k, c} / p_{i, c}}\right)^{1 /\left(1-\rho_{i}\right)} .
$$

Equation (10) says that, when producing the same amount of outputs, the ratio of factor $k$ employed between country $c$ and the US is inversely related to the ratio of factor price of $k$ between the two countries. That is, if factor $k$ in country $c$ is relatively scarce and has a higher factor price than that in the US, industries in country $c$ will use less factor $k$ than their US counterparts in producing the same amount of output.

Recall that $a_{k i, c}$ and $a_{k i, u s}$ are just the elements in the factor intensity matrices $\mathbf{A}_{c}$ and $\mathbf{A}_{u s}$ respectively. Therefore, using equation (10), we can solve for all elements in $\mathbf{A}_{c}$ based on our knowledge of the elements in $\mathbf{A}_{u s}$ and the cross country factor prices.

\subsection{The $\mathrm{HOV}(\mathrm{w})$ model}

The scalar version of the HOV model with differentiated factor intensity techniques (equation (4)) is

$$
\sum_{i} a_{f i, c} E X_{i, c}-\sum_{c^{\prime}, c^{\prime} \neq c} \sum_{i} a_{f i, c^{\prime}} I M_{i, c c^{\prime}}=V_{f, c}-s_{c} V_{f, w}-\left(V_{f, c}^{N}-s_{c} V_{f, w}^{N}\right) .
$$


$a_{f i, c}$ and $a_{f i, c^{\prime}}$ can be inferred by the factor intensity technique inferring method above (equation (10)). Then, the $\operatorname{HOV}(\mathrm{w})$ equation for factor $f$ can be written as

$$
\begin{gathered}
\sum_{i} a_{f i, u s}\left(\frac{w_{f, u s} / p_{i, u s}}{w_{f, c} / p_{i, c}}\right)^{1 /\left(1-\rho_{i}\right)} E X_{i, c}-\sum_{c^{\prime}, c^{\prime} \neq c} \sum_{i} a_{f i, u s}\left(\frac{w_{f, u s} / p_{i, u s}}{w_{f, c^{\prime}} / p_{i, c^{\prime}}}\right)^{1 /\left(1-\rho_{i}\right)} I M_{i, c c^{\prime}} \\
=V_{f, c}-s_{c} V_{f, w}-\left(V_{f, c}^{N}-s_{c} V_{f, w}^{N}\right) .
\end{gathered}
$$

In matrix form, the $\operatorname{HOV}(\mathrm{w})$ model is

$$
\left(\mathbf{A}_{u s} \bullet \mathbf{W}_{c}\right) \mathbf{E X}_{c}-\sum_{c^{\prime}, c^{\prime} \neq c}\left(\mathbf{A}_{u s} \bullet \mathbf{W}_{c^{\prime}}\right) \mathbf{I M}_{c c^{\prime}}=\mathbf{V}_{c}-s_{c} \mathbf{V}_{w}-\left(\mathbf{V}_{c}^{N}-s_{c} \mathbf{V}_{w}^{N}\right)
$$

where "•" is an operator used to denote element by element multiplication. $\mathbf{W}_{c}$ is an $(F \times I)$ matrix that contains elements of $\left[\left(w_{f, u s} / p_{i, u s}\right) /\left(w_{f, c} / p_{i, c}\right)\right]^{1 /\left(1-\rho_{i}\right)}$. The $\mathrm{HOV}(\mathrm{w})$ model builds a relationship between trade and technology, endowments, and factor prices.

Note that when FPE holds, $w_{f, c} / p_{i, c}=w_{f, c^{\prime}} / p_{i, c^{\prime}}=w_{f, u s} / p_{i . u s}$ and $a_{f i, c}=a_{f i, c^{\prime}}=$ $a_{f i, u s}$ for all countries, and the $\mathrm{HOV}(\mathrm{w})$ equation (12) returns to equation (2), the original HOV equation.

\section{Empirical performance}

\subsection{Data and specification}

This paper uses data pertained to 1992 to investigate if the HOV(w) model suggested in the previous section improves the performance of the original HOV model. ${ }^{3}$

The US factor intensity matrix was computed using the US input-output tables and factor usage data from various industrial and population surveys published by the US Department of Commerce. Seven factors, for which the factor price data were available, were included. They are capital and six categories of labor by occupation. The occupations are classified by the International Standard Classification of Occupations, ISCO-1968. They are 1) professional and technical workers, 2) clerical workers, 3) sales workers, 4) service workers, 5) agriculture and forestry workers, fishermen and hunters, and 6) production workers, transportation equipment operators, and laborers.

Factor intensity matrices of other countries were inferred using the factor intensity technique inferring method (equation (10)). Following Trefler (1993), factor price of capital was proxied by the PPP-adjusted investment price obtained from the Penn

\footnotetext{
${ }^{3}$ If the 1992 data were unavailable, the data from the year that is closest to 1992 were adopted with proper adjustments. In the cases when data were missing for a couple of countries, the missing data were proxied by data of a similar adjacent country with suitable adjustments. See the data appendix for details.
} 
World Table (PWT). Wages by occupation were mainly obtained from the Occupational Wages around the World (OWW) database, which is calibrated by Freeman and Oostendorp (2000) based on the ILO October Inquiry database. Production functions of all industries were assumed to take the Cobb-Douglas form for simplicity, such that $\rho_{i}=0$ for all $i$. In this case, the employment of national abundant factor may be overstated if the elasticity of substitution of the actual production function is lower than that of a Cobb-Douglas function; and it may be understated if the elasticity of substitution of the actual production function is higher.

Trade data in the form of total imports and exports by countries were obtained from the International Trade Statistics Yearbook published by the United Nations. The factor services embodied in exports were derived directly by premultiplying the exports data with the factor intensity matrix of the exporting country. The factor services embodied in imports were derived by premultiplying the imports data with a weighted average of factor intensity matrices of the origin countries of the imported goods. The weights are proportional to the volume of imports of country $c$ from these origin countries.

Capital endowments were computed using the perpetual inventory method. Constantprice investment flows were obtained from the PWT. Endowment data for labor were obtained mainly from the databases of International Labor Organization (ILO) and Food and Agriculture Organization (FAO). Countries' shares of world absorption were computed using the PPP-adjusted GDP and domestic absorption data, which were also obtained from the PWT. The "world" factor endowment, $\mathbf{V}_{w}$, is the total factor endowments of 69 countries, which are coming from different regions of the world, with different levels of economic development. In 1992, these countries accounted for around 90 percent of the world trade and world GDP.

Since detailed industrial data for nontradable goods are unavailable for many countries, it is very hard to get satisfactory estimates of the factors employed in nontradable good sectors. Therefore, we set $\mathbf{V}_{c}^{N}-s_{c} \mathbf{V}_{w}^{N}$ in equation (12) equals zero. Ignoring the international differences in relative factor employments in nontradable good sectors is expected to work against the empirical performance of the $\operatorname{HOV}(\mathrm{w})$ model. This disadvantage can be seen by looking at equation (11). Under the conjecture of the $\operatorname{HOV}(\mathrm{w})$ model, if country $c$ is abundant in factor $f\left(V_{f, c}-s_{c} V_{f, w}>0\right)$, the factor price of $f$ may be lower and nontradable good industries in country $c$ will choose factor intensity techniques that use factor $f$ more intensively relative to the world average. Therefore, it is very probable that $V_{f, c}^{N}-s_{c} V_{f, w}^{N}>0$ as well. In another word, the sign of $V_{f, c}^{N}-s_{c} V_{f, w}^{N}$ is expected to be positively correlated to the sign of $V_{f, c}-s_{c} V_{f, w}$. In the cases of missing trade, the absolute value of $V_{f, c}-s_{c} V_{f, w}$ is much larger than that of the $M F C T$; therefore, subtracting $V_{f, c}^{N}-s_{c} V_{f, w}^{N}$ from $V_{f, c}-s_{c} V_{f, w}$ is expected to be able to help the $\operatorname{HOV}(\mathrm{w})$ model to eliminate the missing trade phenomenon in a certain extent. However, as we assumed $\mathbf{V}_{c}^{N}=s_{c} \mathbf{V}_{w}^{N}$, the prediction power of the $\operatorname{HOV}(\mathrm{w})$ model found in this paper may be seriously reduced. 


\subsection{Empirical results and explanations}

Five tests that are commonly used in this literature (e.g. Bowen et al. (1987), Trefler (1995), and Davis and Weinstein (2001)) were used to compare the performance of the original HOV model and the modified $\mathrm{HOV}(\mathrm{w})$ model. They are the sign test, rank test, correlation test, variance ratio test, and the slope test.

The sign test examines the model's prediction in the direction of factor trade. It tests if the sign of $M F C T$ is the same as the sign of $P F C T$. The rank test examines the model's prediction in the magnitude of factor trade. It tests if the ranking of $M F C T$ is consistent with the ranking of $P F C T$. The correlation test calculates the correlation coefficient between $M F C T$ and $P F C T$. The slope test regresses $M F C T$ on PFCT. These two tests test whether the $M F C T$ and $P F C T$ are really related. The variance ratio test calculates the ratio of the variance of $M F C T$ to the variance of PFCT. It examines if the factor trades are "missing" relative to the actual deviations in factor endowments.

These test statistics are given in Table 2. Comparing the HOV and the HOV(w) model, the percentage of correct sign increases from 55 percent to 73 percent. The percentage of correct rankings increases from 57 percent to 68 percent. The improvement in the other three test statistics is more significant. The correlation coefficient of the $\operatorname{HOV}(\mathrm{w})$ model is 0.5 , whereas that of the original HOV model is only 0.17. The slope coefficient of the $\operatorname{HOV}(\mathrm{w})$ model is around 0.24 , whereas that of the HOV model is less than 0.02 . The improvement made by the $\mathrm{HOV}(\mathrm{w})$ model in the prediction of the volume of net factor trade is the most impressive. The variance ratio of the HOV(w) model jumps from HOV model's 0.0098 to 0.2501.

The summary of these test statistics are also depicted graphically using Trefler's (1995) HOV prediction error diagram. The diagram plots the error of prediction $\left(e_{f c}=M F C T_{f c}-P F C T_{f c}\right)$ against the $P F C T_{f c} .{ }^{4}$ Figure 1 shows the prediction error diagram of the original HOV model. The horizontal line with $e_{f c}=0$ represents the prediction of the HOV model. The diagonal line represents the phenomenon of "missing trade", on which the net trade in factor services is 0. Figure 1 reiterates Trefler's (1995) finding that, instead of lying on the horizontal line, all observations of the original HOV model lie very close to the diagonal line. Figure 2 shows the same plot of the $\mathrm{HOV}(\mathrm{w})$ model. From the figure, we can see the observations significantly spread away from the diagonal line of "missing trade".

Although the $\mathrm{HOV}(\mathrm{w})$ model improves the original HOV model in a great extent, its empirical results are still imperfect. The sign test and the rank test are not close to 100 percent. The correlation coefficient, slope coefficient, and the variance ratio are still far from the prediction of the model, which is one. Figure 2 also shows that the observations are not lying perfectly on the horizontal line of $e_{f c}=0$. The previous section has already given us some hints of why these imperfections happen. The

\footnotetext{
${ }^{4}$ To ensure homoscedasticity, all observations with subscript $f c$ were scaled following Trefler (1995).
} 
omission of nontradable good sectors can be a main reason for that. As discussed in the previous section, if we could get the factor employment data in nontradable good sectors for all countries, the absolute value of the PFCT in equation (11) would be decreased and the performance of the $\mathrm{HOV}(\mathrm{w})$ model would be much better. Besides, as in all empirical studies, measurement error and data inconsistency across countries may also be an important contributor to the imperfections.

Nevertheless, it is worth mentioning that the improvements made by the $\mathrm{HOV}(\mathrm{w})$ model here are comparable with the improvements made by Davis and Weinstein (2001) in their T5 specification, which features the Helpman no-FPE model and makes similar assumptions as the $\mathrm{HOV}(\mathrm{w})$ model does in this paper. ${ }^{5}$ This may convince us that the factor intensity matrices computed by the factor intensity technique inferring method introduced in this paper are not bad approximations to the true factor intensity matrices, and the inferring method is an acceptable method in estimating the differentiated factor intensity techniques across countries.

\section{Conclusion}

The HOV model had performed poorly in decades of empirical analyses. The empirical failure of the model is suspected to be caused by one of its key assumptions about production: the assumption of internationally identical factor intensity techniques. Nevertheless, relaxing this assumption is not an easy task. To compute the differentiated factor intensity techniques applied in different countries, we need to collect detailed input-output tables and factor usage data of each individual country, and these data are unavailable for many countries, especially the developing countries.

This paper took an alternative approach by introducing a factor intensity technique inferring method, such that, even in the absence of national input-output data, we can still infer the factor intensity techniques of countries all over the world. Using the inferring method, this paper computed the factor intensity techniques of 69 countries.

A modified HOV model that adapts the inferring method was built and named as the $\mathrm{HOV}(\mathrm{w})$ model. It added one more important factor to the original HOV model: the international relative factor prices. After relaxing the identical factor intensity techniques assumption and implementing the computed factor intensity techniques, the $\operatorname{HOV}(\mathrm{w})$ model performed much better than the original HOV model. The improvement is comparable to the results obtained by Davis and Weinstein (2001). The performance of the $\mathrm{HOV}(\mathrm{w})$ model is expected to be improved even further if data of factors employed in nontradable good sectors were available and subtracted from the PFCT.

\footnotetext{
${ }^{5}$ More favorable assumptions were made in Davis and Weinstein's T6 and T7 specifications and it will not be fare to compare the performance of the $\mathrm{HOV}(\mathrm{w})$ model with these two specifications.
} 


\section{Data Appendix}

Factor intensity techniques applied in the US were computed using the US inputoutput (I-O) table and factor usage data. I-O data were obtained from the Benchmark Input-Output Accounts of the United States, 1992. 2-digit I-O data, for which establishments were grouped into 96 industries, were used. Although data in a finer 6-digit I-O industry classification are available, they were not used because data in other classifications were to be converted into I-O classifications, and conversions at finer levels are not reliable. Direct capital input is the tangible wealth estimates provided by the Bureau of Economic Analysis (BEA). As the industry classifications of the BEA estimates are not detailed enough (equivalent to 2-digit SIC level only), assets data provided by Bureau of the Census and the Internal Revenue Service were used to prorate the BEA estimates to detailed SIC levels. The data were then converted into I-O codes using the concordance provided in the Benchmark IO Accounts. Direct labor input is the labor employment by occupation in each industry extracted from the Current Population Survey. Personal data under 3-digit CPS industry code and occupation major recode were adopted. They were first converted into SIC, and then into I-O classifications. Employment data published in corresponding industry and government censuses, which are not divided into different occupations, were used as weights if needed.

Factor price of capital is the 1992 PPP-adjusted investment price index obtained from the Penn World Table Mark 5.6 and 6.0 (PWT). Factor price of labor by occupation is mainly the base calibration with lexicographic weighting obtained from the Occupational Wages around the World (OWW) database. Exchange rates from the IMF were used to convert the wage rates of all countries into US dollar. Since the ratio of wage rates between other countries and the US is needed, we need wage rate data of the same occupation in both the US and the country in concern. If there is no matching occupation, the ratio of wage rates between the country in concern and Germany, which has more detailed occupational wage data than the US, was taken. The ratio was then multiplied with the ratio of wages rates in the same ISCO group between Germany and the US to get the ratio between that country and the US. If wage rates of a particular ISCO group are not available, the ratio of another ISCO group that is close to that group was used. For countries that wages were unavailable in the OWW, their wages were proxied by the wages of a similar adjacent country adjusted to either the wages in manufacturing (from the International Labour Office (ILO) database) or the PPP-adjusted GDP per capita (from the PWT). It should be noted that the wage data of different countries collected in the ILO are not based on the same working time horizon, hourly rates and daily rates were multiplied with estimated working hours per month and working days per month respectively.

Trade data were obtained from issues of International Trade Statistics Yearbook. Because the commodity trade data are published at different digit levels of SITC, the commodity items published in the Trade Yearbook are not mutually exclusive. Differences between every two different levels of aggregation were taken to get trade 
data of mutually exclusive commodity classifications. The trade data are in SITC rev.2. They were first converted into SITC rev.3. The concordance between SITC rev.2 and SITC rev.3 was constructed using the concordance of 10-digit HS to 5digit SITC rev.2 and the concordance of 10-digit HS to 5-digit SITC rev.3, which are collected by Jon Haveman from the NBER Trade Data CD. The data under SITC rev.3 were then converted into SIC using the concordance provided in the U.S. Exports History CDROM. Finally, the trade data were converted into IO classifications.

Capital endowment data were constructed using the perpetual inventory method. Real investment flows of countries in 1985 international dollars were obtained from the PWT. The capital endowment data were matched with the capital intensity data by converting the 1992 US capital intensity data into 1985 international dollar. The conversion factor is the international investment deflator divided by the US investment price level. Both the deflator and the price level were obtained from the PWT. When the investment data were missing for a couple of years, the real gross domestic investment data obtained from the World Tables were used to estimate the growth rates of investment and the missing data were filled by multiplying the PWT investment data to the corresponding growth rates. Labor endowment data are the economically active population or the sum of employment and unemployment (previously employed). Most of the data were obtained from the ILO. Others were obtained from the corresponding national or regional statistical departments. For a couple of Latin American countries that report urban labor force only, the agricultural related workers were estimated using the labor force data obtained from the Food and Agriculture Organization.

Shares of world absorption were computed using the data of real GDP, consumption, investment, and government expenditure obtained from the PWT. If the data for 1992 were unavailable in the PWT, the real GDP and domestic absorption recorded in the World Tables were used to compute their growth rates and the missing data were derived by applying the growth rates to the PWT data in other years.

\section{References}

[1] Bowen, Harry P.; Leamer, Edward E.; and Sveikauskas, Leo, "Multicountry, Multifactor Tests of the Factor Abundance Theory." American Economic Review, December 1987, 77(5), pp. 791-809.

[2] Davis, Donald R. and Weinstein, David E., "An Account of Global Factor Trade." American Economic Review, December 2001, 91(5), pp. 1423-1453.

[3] Davis, Donald R.; Weinstein, David E.; Bradford, Scott C.; and Shimpo, Kazushige, "Using International and Japanese Regional Data to Determine When the Factor Abundance Theory of Trade Works." American Economic Review, June 1997, 87(3), pp. 421-446. 
[4] Estevadeordal, Antoni and Taylor, Alan M., "A Century of Missing Trade?" American Economic Review, March 2002, 92(1), pp. 383-393.

[5] Freeman, Richard B. and Oostendorp, Remco H., "Wages Around the World: Pay Across Occupations and Countries", NBER Working Paper No. 8058, December 2000.

[6] Hakura, Dalia S., "Why Does HOV Fail? The Role of Technological Differences within the EC." Journal of International Economics, August 2001, 54(2), pp. 361-382.

[7] Helpman, Elhanan, "The Structure of Foreign Trade." Journal of Economic Perspectives, 13(2), Spring 1999, pp. 121-144.

[8] Leamer, Edward E., Sources of International Comparative Advantage: Theory and Evidence, Cambridge, MA: MIT Press, 1984.

[9] Leamer, Edward E. and Levinsohn, James, "International Trade Theory: The Evidence." in Gene Grossman and Kenneth Rogoff, eds., Handbook of International Economics, Vol. 3, Amsterdam: North-Holland, 1995, pp. 1339-94.

[10] Leontief, Wassily W., "Domestic Production and Foreign Trade: The American Capital Position Re-examined." Proceedings of the American Philosophical Society, September 1953, 97(4), pp. 332-49. Reprinted in Richard E. Caves and Harry G. Johnson, Readings in International Economics, Homewood, Ill.: Irwin, 1968 .

[11] Maskus, Keith E., "A Test of the Heckscher-Ohlin-Vanek Theorem: The Leontief Commonplace." Journal of International Economics, 19, November 1985, pp.20112.

[12] Staiger, Robert W., "A Specification Test of the Heckscher-Ohlin Theory," Journal of International Economics, 25, August 1988, pp. 129-41.

[13] Summers, Robert and Heston, Alan, "The Penn World Table (Mark 5): An Expanded Set of International Comparisons, 1950-1988." Quarterly Journal of Economics, 106, May 1991, pp. 327-68.

[14] Trefler, Daniel, "International Factor Price Differences: Leontief was Right!" Journal of Political Economy, December 1993, 101(6), pp. 961-87.

[15] Trefler, Daniel, "The Cases of the Missing Trade and Other Mysteries." American Economic Review, December 1995, 85(5), pp. 1029-1046.

[16] Vanek, Jaroslav, "The Factor Proportions Theory: The N-Factor Case." Kyklos, October 1968, 21(4), pp. 749-56. 
Table 1a: Factor Prices Relative to the US $\left(w_{c} / w_{u s}\right)$

\begin{tabular}{|c|c|c|c|c|c|c|c|}
\hline \multirow[b]{2}{*}{ Countries } & \multirow[b]{2}{*}{ Capital } & \multicolumn{6}{|c|}{ Labor by occupation in ISCO-1968 } \\
\hline & & $0 / 1$ & 3 & 4 & 5 & 6 & $7 / 8 / 9$ \\
\hline Algeria & 1.10 & 0.09 & 0.13 & 0.15 & 0.17 & 0.22 & 0.14 \\
\hline Argentina & 0.95 & 0.31 & 0.23 & 0.37 & 0.31 & 0.27 & 0.41 \\
\hline Australia & 1.06 & 0.98 & 1.25 & 1.35 & 1.44 & 1.07 & 1.41 \\
\hline Austria & 1.41 & 1.39 & 1.40 & 0.93 & 1.07 & 1.34 & 1.16 \\
\hline Bangladesh & 0.51 & 0.02 & 0.02 & 0.02 & 0.03 & 0.03 & 0.02 \\
\hline Belgium & 1.17 & 0.68 & 1.27 & 1.19 & 1.19 & 1.60 & 1.53 \\
\hline Brazil & 0.60 & 0.27 & 0.20 & 0.20 & 0.24 & 0.19 & 0.14 \\
\hline Bulgaria & 0.78 & 0.06 & 0.12 & 0.11 & 0.11 & 0.18 & 0.11 \\
\hline Canada & 0.91 & 1.30 & 1.09 & 1.43 & 1.43 & 1.15 & 1.15 \\
\hline Chile & 0.68 & 0.52 & 0.17 & 0.28 & 0.12 & 0.31 & 0.31 \\
\hline China & 0.39 & 0.02 & 0.04 & 0.04 & 0.04 & 0.02 & 0.02 \\
\hline Colombia & 0.63 & 0.24 & 0.10 & 0.10 & 0.14 & 0.12 & 0.13 \\
\hline Costa Rica & 0.83 & 0.10 & 0.12 & 0.21 & 0.20 & 0.21 & 0.10 \\
\hline Cyprus & 1.03 & 0.93 & 1.12 & 0.79 & 1.26 & 0.89 & 1.05 \\
\hline Czech Republic & 0.43 & 0.05 & 0.08 & 0.11 & 0.13 & 0.10 & 0.10 \\
\hline Denmark & 1.46 & 1.22 & 1.60 & 1.72 & 2.50 & 1.27 & 1.42 \\
\hline Dominican Rep. & 0.73 & 0.09 & 0.07 & 0.07 & 0.15 & 0.73 & 0.11 \\
\hline Ecuador & 0.50 & 0.18 & 0.07 & 0.08 & 0.10 & 0.09 & 0.10 \\
\hline Egypt & 1.08 & 0.06 & 0.09 & 0.08 & 0.10 & 0.07 & 0.06 \\
\hline El Salvador & 0.79 & 0.06 & 0.07 & 0.12 & 0.11 & 0.12 & 0.06 \\
\hline Finland & 1.19 & 0.98 & 1.18 & 1.39 & 1.56 & 1.30 & 1.56 \\
\hline France & 1.22 & 1.14 & 0.72 & 1.19 & 1.05 & 1.29 & 1.21 \\
\hline Germany & 1.41 & 1.75 & 1.11 & 1.83 & 1.61 & 1.98 & 1.86 \\
\hline Greece & 1.06 & 0.56 & 0.36 & 0.58 & 0.51 & 0.63 & 0.60 \\
\hline Guatemala & 0.78 & 0.05 & 0.06 & 0.11 & 0.11 & 0.11 & 0.06 \\
\hline Honduras & 0.71 & 0.14 & 0.10 & 0.14 & 0.08 & 0.09 & 0.07 \\
\hline Hong Kong & 1.06 & 0.45 & 0.92 & 0.53 & 0.75 & 1.00 & 1.00 \\
\hline Hungary & 0.73 & 0.14 & 0.11 & 0.18 & 0.20 & 0.17 & 0.10 \\
\hline India & 0.47 & 0.05 & 0.05 & 0.02 & 0.03 & 0.02 & 0.07 \\
\hline Indonesia & 0.44 & 0.11 & 0.12 & 0.06 & 0.11 & 0.04 & 0.04 \\
\hline Iran & 1.55 & 0.50 & 0.58 & 0.82 & 0.82 & 0.61 & 0.50 \\
\hline Ireland & 1.17 & 1.17 & 1.33 & 0.99 & 1.33 & 1.39 & 1.27 \\
\hline Israel & 0.90 & 0.66 & 0.42 & 0.69 & 0.61 & 0.75 & 0.71 \\
\hline Italy & 1.26 & 1.14 & 1.62 & 1.45 & 1.82 & 1.53 & 1.78 \\
\hline Japan & 1.53 & 2.22 & 1.10 & 1.05 & 2.07 & 3.05 & 1.70 \\
\hline Korea & 0.75 & 0.64 & 0.53 & 0.60 & 0.71 & 0.62 & 0.62 \\
\hline Malaysia & 0.69 & 0.07 & 0.16 & 0.16 & 0.15 & 0.08 & 0.15 \\
\hline Mexico & 0.79 & 0.17 & 0.20 & 0.16 & 0.21 & 0.23 & 0.20 \\
\hline Morocco & 0.66 & 0.07 & 0.11 & 0.10 & 0.13 & 0.08 & 0.07 \\
\hline Netherlands & 1.32 & 0.98 & 0.98 & 1.63 & 1.63 & 1.62 & 1.38 \\
\hline New Zealand & 0.91 & 0.98 & 1.01 & 0.84 & 1.01 & 0.68 & 1.01 \\
\hline Nigeria & 1.24 & 0.10 & 0.03 & 0.05 & 0.05 & 0.02 & 0.02 \\
\hline Norway & 1.43 & 0.87 & 1.76 & 1.84 & 1.74 & 1.55 & 1.17 \\
\hline Pakistan & 0.50 & 0.09 & 0.09 & 0.04 & 0.05 & 0.04 & 0.11 \\
\hline Panama & 0.72 & 0.54 & 0.22 & 0.23 & 0.31 & 0.26 & 0.29 \\
\hline Paraguay & 0.67 & 0.29 & 0.08 & 0.28 & 0.14 & 0.33 & 0.33 \\
\hline
\end{tabular}


Table 1a: Factor Prices Relative to the US (cont.)

\begin{tabular}{|c|c|c|c|c|c|c|c|}
\hline \multirow[b]{2}{*}{ Countries } & \multirow[b]{2}{*}{ Capital } & \multicolumn{6}{|c|}{ Labor by occupation in ISCO-1968 } \\
\hline & & $0 / 1$ & 3 & 4 & 5 & 6 & $7 / 8 / 9$ \\
\hline Philippines & 0.51 & 0.05 & 0.11 & 0.11 & 0.10 & 0.06 & 0.10 \\
\hline Poland & 0.48 & 0.10 & 0.15 & 0.16 & 0.20 & 0.18 & 0.10 \\
\hline Portugal & 1.03 & 0.67 & 0.62 & 0.46 & 0.49 & 0.48 & 0.43 \\
\hline Romania & 0.47 & 0.04 & 0.05 & 0.07 & 0.07 & 0.10 & 0.05 \\
\hline Singapore & 0.85 & 1.13 & 0.63 & 0.69 & 0.56 & 0.46 & 0.46 \\
\hline Sloveri & 0.75 & 0.22 & 0.37 & 0.44 & 0.50 & 0.49 & 0.27 \\
\hline South Africa & 1.08 & 0.95 & 0.34 & 0.84 & 0.34 & 0.25 & 0.27 \\
\hline Spain & 1.22 & 1.28 & 0.81 & 1.34 & 1.18 & 1.45 & 1.36 \\
\hline Sri Lanka & 0.54 & 0.03 & 0.05 & 0.03 & 0.05 & 0.02 & 0.02 \\
\hline Sweden & 1.59 & 0.78 & 1.86 & 2.12 & 2.12 & 2.19 & 1.86 \\
\hline Switzerland & 1.57 & 2.14 & 1.36 & 2.23 & 1.97 & 2.43 & 2.28 \\
\hline Syria & 1.99 & 0.52 & 0.52 & 0.52 & 0.52 & 0.52 & 0.52 \\
\hline Taiwan & 1.21 & 0.70 & 0.57 & 0.65 & 0.77 & 0.68 & 0.68 \\
\hline Thailand & 0.43 & 0.20 & 0.21 & 0.10 & 0.20 & 0.08 & 0.08 \\
\hline Trinidad & 1.29 & 0.58 & 0.63 & 0.27 & 0.31 & 0.53 & 0.69 \\
\hline Tunisia & 0.92 & 0.11 & 0.16 & 0.14 & 0.18 & 0.12 & 0.11 \\
\hline Turkey & 0.73 & 0.28 & 0.52 & 0.24 & 0.24 & 0.57 & 0.57 \\
\hline UK & 1.12 & 1.22 & 1.39 & 1.03 & 1.39 & 1.45 & 1.33 \\
\hline Uruguay & 0.69 & 0.46 & 0.12 & 0.46 & 0.22 & 0.53 & 0.53 \\
\hline USA & 1.00 & 1.00 & 1.00 & 1.00 & 1.00 & 1.00 & 1.00 \\
\hline USSR, Former & 0.19 & 0.01 & 0.39 & 0.33 & 0.36 & 0.66 & 0.02 \\
\hline Venezuela & 0.67 & 0.13 & 0.17 & 0.09 & 0.11 & 0.09 & 0.15 \\
\hline Zimbabwe & 0.40 & 0.24 & 0.09 & 0.22 & 0.09 & 0.07 & 0.07 \\
\hline Mean & 0.91 & 0.54 & 0.53 & 0.58 & 0.62 & 0.64 & 0.59 \\
\hline St. Dev. & 0.37 & 0.53 & 0.52 & 0.59 & 0.65 & 0.67 & 0.60 \\
\hline$(1-$ Mean)/SD & 0.24 & 0.87 & 0.91 & 0.72 & 0.59 & 0.55 & 0.69 \\
\hline Median & 0.85 & 0.31 & 0.23 & 0.28 & 0.31 & 0.46 & 0.31 \\
\hline (1 - Median)/SD & 0.40 & 1.30 & 1.47 & 1.22 & 1.07 & 0.81 & 1.15 \\
\hline 1st Quartile & 0.67 & 0.10 & 0.11 & 0.11 & 0.12 & 0.10 & 0.10 \\
\hline$(1-1$ st $Q) / S D$ & 0.90 & 1.70 & 1.71 & 1.52 & 1.36 & 1.35 & 1.49 \\
\hline 3rd Quartile & 1.17 & 0.95 & 0.98 & 0.93 & 1.05 & 1.00 & 1.05 \\
\hline$(1-3 r d Q) / S D$ & -0.47 & 0.09 & 0.04 & 0.12 & -0.07 & 0.00 & -0.09 \\
\hline
\end{tabular}

Sources: Factor price of capital was proxied by the PPP-adjusted investment price obtained from the Penn World Tables. Wages by occupation were estimated based on the Occupational Wages around the World database calibrated by Freeman and Oostendorp (2000), the LABORSTA database by International Labor Office, and the GDP per capita from the Penn World Tables. Notes: Occupations are classified by International Standard Classification of Occupations ISCO1968. Class 0/1 is professional and technical workers; class 3 is clerical workers; class 4 is sales workers; class 5 is service workers; class 6 is agriculture and forestry workers, fishermen and hunters; and class 7/8/9 is production workers, transportation equipment operators, and laborers. 
Table 1b: Relative Factor Prices Relative to the US

$$
\left[\left(w_{l, c} / w_{k, c}\right) /\left(w_{l, u s} / w_{k, u s}\right)\right]
$$

\begin{tabular}{|c|c|c|c|c|c|c|c|}
\hline \multirow[b]{2}{*}{ Countries } & \multirow[b]{2}{*}{ Capital } & \multicolumn{6}{|c|}{ Labor by occupation in ISCO-1968 } \\
\hline & & $0 / 1$ & 3 & 4 & 5 & 6 & $7 / 8 / 9$ \\
\hline Algeria & 1.00 & 0.08 & 0.11 & 0.13 & 0.16 & 0.20 & 0.12 \\
\hline Argentina & 1.00 & 0.33 & 0.24 & 0.39 & 0.33 & 0.28 & 0.43 \\
\hline Australia & 1.00 & 0.92 & 1.18 & 1.28 & 1.36 & 1.01 & 1.33 \\
\hline Austria & 1.00 & 0.98 & 0.99 & 0.66 & 0.75 & 0.94 & 0.82 \\
\hline Bangladesh & 1.00 & 0.05 & 0.05 & 0.04 & 0.05 & 0.07 & 0.04 \\
\hline Belgium & 1.00 & 0.58 & 1.09 & 1.01 & 1.01 & 1.37 & 1.31 \\
\hline Brazil & 1.00 & 0.46 & 0.33 & 0.33 & 0.41 & 0.32 & 0.24 \\
\hline Bulgaria & 1.00 & 0.07 & 0.15 & 0.14 & 0.14 & 0.23 & 0.15 \\
\hline Canada & 1.00 & 1.43 & 1.20 & 1.58 & 1.58 & 1.26 & 1.26 \\
\hline Chile & 1.00 & 0.77 & 0.25 & 0.42 & 0.18 & 0.46 & 0.46 \\
\hline China & 1.00 & 0.04 & 0.09 & 0.10 & 0.09 & 0.05 & 0.05 \\
\hline Colombia & 1.00 & 0.38 & 0.15 & 0.16 & 0.22 & 0.19 & 0.20 \\
\hline Costa Rica & 1.00 & 0.12 & 0.14 & 0.25 & 0.24 & 0.25 & 0.13 \\
\hline Cyprus & 1.00 & 0.90 & 1.09 & 0.76 & 1.22 & 0.86 & 1.02 \\
\hline Czech Republic & 1.00 & 0.13 & 0.20 & 0.26 & 0.31 & 0.23 & 0.23 \\
\hline Denmark & 1.00 & 0.83 & 1.10 & 1.18 & 1.71 & 0.87 & 0.97 \\
\hline Dominican Rep. & 1.00 & 0.12 & 0.09 & 0.10 & 0.20 & 1.00 & 0.15 \\
\hline Ecuador & 1.00 & 0.36 & 0.15 & 0.15 & 0.21 & 0.18 & 0.19 \\
\hline Egypt & 1.00 & 0.05 & 0.08 & 0.07 & 0.09 & 0.06 & 0.05 \\
\hline El Salvador & 1.00 & 0.07 & 0.09 & 0.15 & 0.15 & 0.15 & 0.08 \\
\hline Finland & 1.00 & 0.83 & 0.99 & 1.17 & 1.31 & 1.09 & 1.31 \\
\hline France & 1.00 & 0.93 & 0.59 & 0.97 & 0.86 & 1.06 & 0.99 \\
\hline Germany & 1.00 & 1.24 & 0.79 & 1.29 & 1.14 & 1.40 & 1.32 \\
\hline Greece & 1.00 & 0.53 & 0.34 & 0.55 & 0.49 & 0.60 & 0.56 \\
\hline Guatemala & 1.00 & 0.07 & 0.08 & 0.14 & 0.14 & 0.14 & 0.07 \\
\hline Honduras & 1.00 & 0.19 & 0.14 & 0.20 & 0.12 & 0.13 & 0.10 \\
\hline Hong Kong & 1.00 & 0.42 & 0.86 & 0.50 & 0.70 & 0.94 & 0.94 \\
\hline Hungary & 1.00 & 0.19 & 0.15 & 0.24 & 0.27 & 0.23 & 0.14 \\
\hline India & 1.00 & 0.11 & 0.11 & 0.05 & 0.06 & 0.05 & 0.14 \\
\hline Indonesia & 1.00 & 0.25 & 0.27 & 0.13 & 0.25 & 0.10 & 0.10 \\
\hline Iran & 1.00 & 0.32 & 0.37 & 0.53 & 0.53 & 0.40 & 0.32 \\
\hline Ireland & 1.00 & 1.00 & 1.14 & 0.85 & 1.14 & 1.19 & 1.09 \\
\hline Israel & 1.00 & 0.73 & 0.47 & 0.77 & 0.67 & 0.83 & 0.78 \\
\hline Italy & 1.00 & 0.90 & 1.29 & 1.15 & 1.44 & 1.22 & 1.42 \\
\hline Japan & 1.00 & 1.45 & 0.72 & 0.69 & 1.35 & 1.99 & 1.11 \\
\hline Korea & 1.00 & 0.86 & 0.70 & 0.81 & 0.95 & 0.83 & 0.83 \\
\hline Malaysia & 1.00 & 0.11 & 0.23 & 0.23 & 0.22 & 0.12 & 0.22 \\
\hline Mexico & 1.00 & 0.22 & 0.25 & 0.20 & 0.27 & 0.29 & 0.25 \\
\hline Morocco & 1.00 & 0.11 & 0.17 & 0.15 & 0.19 & 0.13 & 0.11 \\
\hline Netherlands & 1.00 & 0.74 & 0.74 & 1.23 & 1.23 & 1.22 & 1.04 \\
\hline New Zealand & 1.00 & 1.08 & 1.10 & 0.92 & 1.10 & 0.74 & 1.10 \\
\hline Nigeria & 1.00 & 0.08 & 0.02 & 0.04 & 0.04 & 0.01 & 0.02 \\
\hline Norway & 1.00 & 0.61 & 1.23 & 1.29 & 1.22 & 1.08 & 0.82 \\
\hline Pakistan & 1.00 & 0.17 & 0.17 & 0.07 & 0.10 & 0.08 & 0.23 \\
\hline Panama & 1.00 & 0.75 & 0.31 & 0.32 & 0.43 & 0.37 & 0.40 \\
\hline Paraguay & 1.00 & 0.43 & 0.11 & 0.42 & 0.20 & 0.49 & 0.49 \\
\hline
\end{tabular}


Table 1b: Relative Factor Prices Relative to the US (cont.)

\begin{tabular}{|c|c|c|c|c|c|c|c|}
\hline \multirow[b]{2}{*}{ Countries } & \multirow[b]{2}{*}{ Capital } & \multicolumn{6}{|c|}{ Labor by occupation in ISCO-1968 } \\
\hline & & $0 / 1$ & 3 & 4 & 5 & 6 & $7 / 8 / 9$ \\
\hline Philippines & 1.00 & 0.10 & 0.21 & 0.21 & 0.20 & 0.11 & 0.20 \\
\hline Poland & 1.00 & 0.21 & 0.31 & 0.33 & 0.41 & 0.38 & 0.21 \\
\hline Portugal & 1.00 & 0.65 & 0.60 & 0.45 & 0.48 & 0.47 & 0.42 \\
\hline Romania & 1.00 & 0.10 & 0.10 & 0.14 & 0.16 & 0.21 & 0.12 \\
\hline Singapore & 1.00 & 1.33 & 0.73 & 0.81 & 0.65 & 0.54 & 0.54 \\
\hline Slovenia & 1.00 & 0.29 & 0.49 & 0.58 & 0.66 & 0.65 & 0.35 \\
\hline South Africa & 1.00 & 0.88 & 0.31 & 0.78 & 0.31 & 0.23 & 0.25 \\
\hline Spain & 1.00 & 1.05 & 0.67 & 1.10 & 0.97 & 1.19 & 1.12 \\
\hline Sri Lanka & 1.00 & 0.05 & 0.09 & 0.05 & 0.09 & 0.04 & 0.04 \\
\hline Sweden & 1.00 & 0.49 & 1.17 & 1.34 & 1.34 & 1.38 & 1.17 \\
\hline Switzerland & 1.00 & 1.37 & 0.87 & 1.43 & 1.26 & 1.55 & 1.46 \\
\hline Syria & 1.00 & 0.26 & 0.26 & 0.26 & 0.26 & 0.26 & 0.26 \\
\hline Taiwan & 1.00 & 0.58 & 0.47 & 0.54 & 0.63 & 0.56 & 0.56 \\
\hline Thailand & 1.00 & 0.47 & 0.49 & 0.24 & 0.46 & 0.18 & 0.18 \\
\hline Trinidad & 1.00 & 0.45 & 0.49 & 0.21 & 0.24 & 0.41 & 0.53 \\
\hline Tunisia & 1.00 & 0.11 & 0.17 & 0.16 & 0.20 & 0.13 & 0.12 \\
\hline Turkey & 1.00 & 0.39 & 0.71 & 0.33 & 0.33 & 0.78 & 0.78 \\
\hline UK & 1.00 & 1.09 & 1.24 & 0.92 & 1.23 & 1.29 & 1.18 \\
\hline Uruguay & 1.00 & 0.66 & 0.18 & 0.66 & 0.32 & 0.76 & 0.76 \\
\hline USA & 1.00 & 1.00 & 1.00 & 1.00 & 1.00 & 1.00 & 1.00 \\
\hline USSR, Former & 1.00 & 0.03 & 2.06 & 1.72 & 1.87 & 3.43 & 0.10 \\
\hline Venezuela & 1.00 & 0.19 & 0.25 & 0.14 & 0.16 & 0.14 & 0.23 \\
\hline Zimbabwe & 1.00 & 0.60 & 0.22 & 0.53 & 0.22 & 0.16 & 0.17 \\
\hline Mean & & 0.51 & 0.51 & 0.55 & 0.58 & 0.62 & 0.54 \\
\hline St. Dev. & & 0.40 & 0.43 & 0.45 & 0.49 & 0.58 & 0.45 \\
\hline$(1-$ Mean)/SD & & 1.21 & 1.13 & 1.01 & 0.85 & 0.66 & 1.04 \\
\hline Median & & 0.43 & 0.31 & 0.42 & 0.33 & 0.41 & 0.35 \\
\hline (1 - Median)/SD & & 1.42 & 1.58 & 1.31 & 1.36 & 1.01 & 1.44 \\
\hline 1st Quartile & & 0.12 & 0.15 & 0.16 & 0.20 & 0.18 & 0.15 \\
\hline$(1-1 s t Q) / S D$ & & 2.18 & 1.94 & 1.89 & 1.62 & 1.41 & 1.91 \\
\hline 3rd Quartile & & 0.83 & 0.79 & 0.85 & 1.00 & 1.00 & 0.97 \\
\hline$(1-3 r d Q) / S D$ & & 0.41 & 0.49 & 0.34 & 0.00 & 0.00 & 0.06 \\
\hline
\end{tabular}

Sources: Factor price of capital was proxied by the PPP-adjusted investment price obtained from the Penn World Tables. Wages by occupation were estimated based on the Occupational Wages around the World database calibrated by Freeman and Oostendorp (2000), the LABORSTA database by International Labor Office, and the GDP per capita from the Penn World Tables. Notes: Occupations are classified by International Standard Classification of Occupations ISCO1968. Class 0/1 is professional and technical workers; class 3 is clerical workers; class 4 is sales workers; class 5 is service workers; class 6 is agriculture and forestry workers, fishermen and hunters; and class 7/8/9 is production workers, transportation equipment operators, and laborers. 
Table 2: Performance Tests on the HOV and the HOV(w) Models

\begin{tabular}{l|cc}
\hline & HOV & HOV $(w)$ \\
\hline Sign test & 0.5539 & 0.7343 \\
Rank test & 0.5687 & 0.6759 \\
Correlation & 0.1699 & 0.4966 \\
Slope Test & 0.0160 & 0.2422 \\
(95\% confidence interval) & $(0.0064,0.0257)$ & $0.1986,02858)$ \\
Variance ratio test & 0.0098 & 0.2501 \\
\hline
\end{tabular}




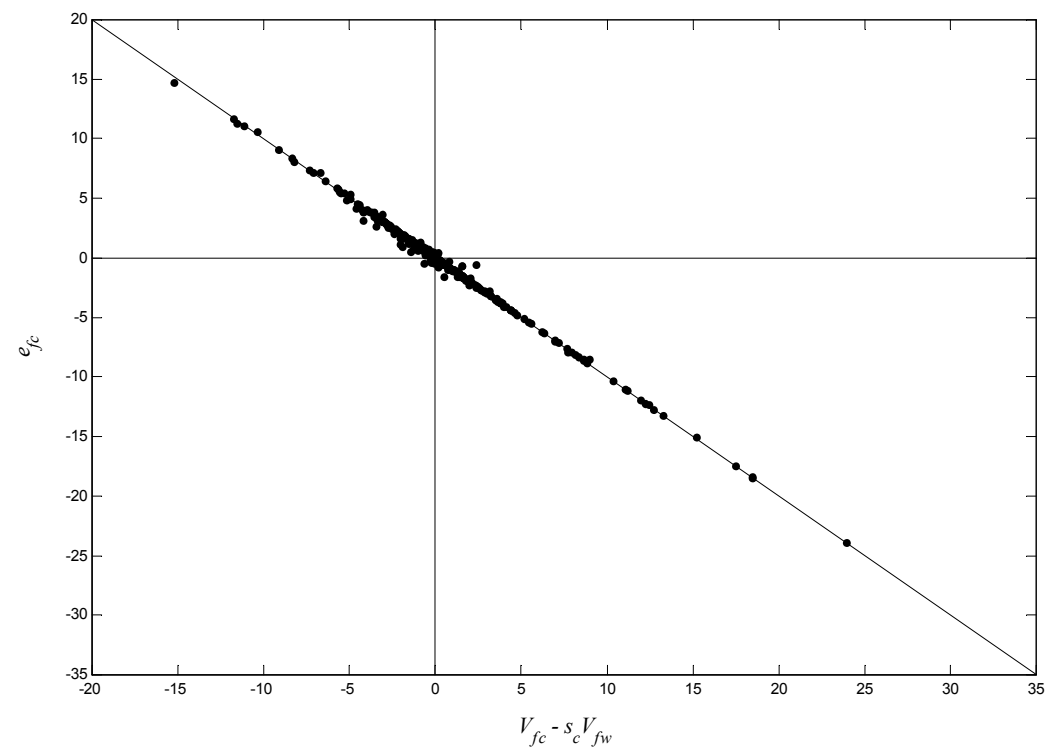

Figure 1: Plot of $e_{f c}$ against the $P F C T_{f c}$ for the original HOV model

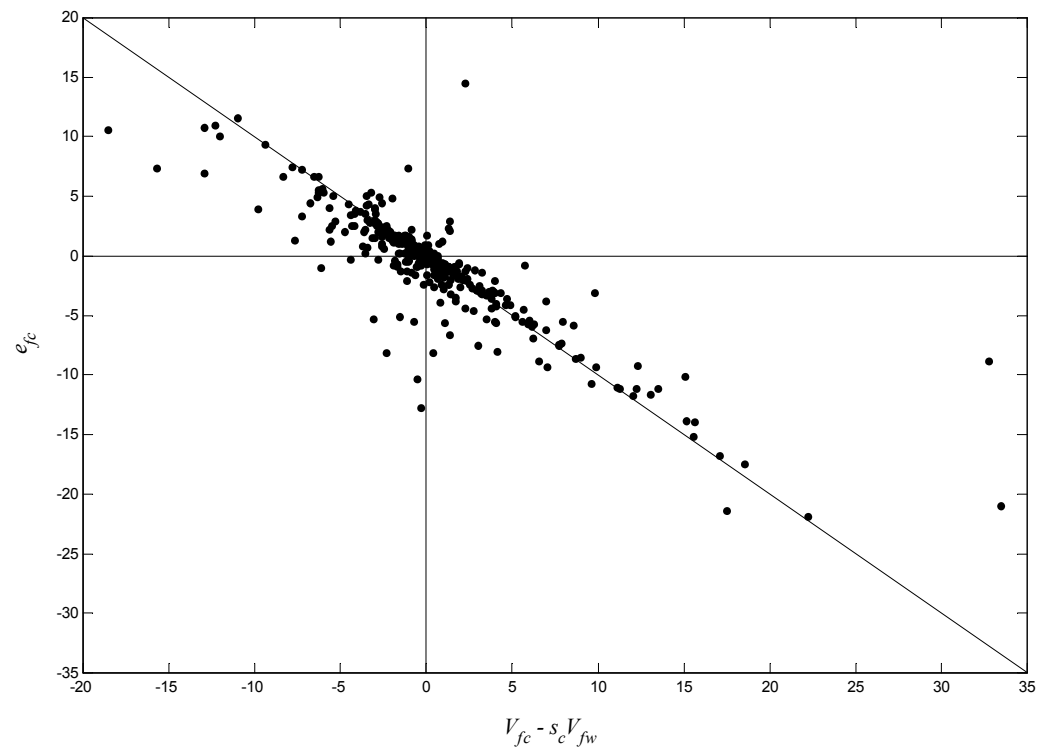

Figure 2: Plot of $e_{f c}$ against the $P F C T_{f c}$ for the $\operatorname{HOV}(\mathrm{w})$ model 